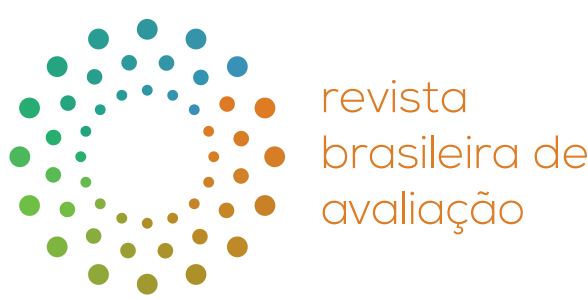

\title{
Estudo apreciativo da governança do Marco Legal da Primeira Infância no Brasil
}

\author{
Appreciative study of early childhood legal framework in Brazil \\ Cristina Kiomi Mori ${ }^{1,2 *}$ (1) [Branca], Ana Karolina Andrade² (1) [Branca] \\ ${ }^{1}$ Insper Instituto de Ensino e Pesquisa (Insper), Programa Avançado de Gestão Pública, São Paulo, SP, Brasil \\ ${ }^{2}$ Pacto Organizações Regenerativas, São Paulo, SP, Brasil
}

COMO CITAR: Mori, Cristina Kiomi, \& Andrade, Ana Karolina. (2021). Estudo apreciativo da governança do Marco Legal da Primeira Infância no Brasil. Revista Brasileira de Avaliação, 10(1), e100921. https://doi. org/10.4322/rbaval202110009

\section{Resumo}

O presente ensaio apresenta achados preliminares sobre a constituição de comitês intersetoriais da política integrada para a primeira infância em diferentes esferas governamentais no Brasil. Principal estratégia de governança definida para a implementação do Marco Legal da Primeira Infância, os comitês visam promover a integração entre as políticas setoriais e, desta forma, efetivar uma política pública de atenção integral e integrada ao desenvolvimento infantil. O estudo, conduzido sob a forma de investigação apreciativa, teve como foco boas práticas e desafios comumente enfrentados na trajetória de amadurecimento de comitês instituídos em quatro instâncias: federal, estadual, regional (região interna do estado) e municipal. Mostrou evidências de que esta estrutura de governança contribui para efetivar, paulatinamente, a intersetorialidade na implementação da política pública. Concluiu pela relevância da combinação de quatro aspectos para o amadurecimento dos comitês: i) institucionalidade garantida em leis e normas; ii) prioridade política dada à agenda; iii) engajamento dos integrantes; e iv) manutenção de um pulso de reuniões.

Palavras-chave: Primeira infância. Governança. Intersetorialidade. Implementação. Comitês.

\begin{abstract}
This essay presents preliminar findings about the constitution of early childhood integrated policy intersectoral committees in different governmental levels in Brazil. Main governance strategy defined to implement Early Childhood Legal Framework, the committees aim to promote integration among sectoral policies and, thus, bring to practice a comprehensive and integrated public policy for child care and development. Conducted as an appreciative study, it focused on best practices and challenges often faced in the committee's maturation trajectory, instituted in four different levels: federal, state, regional (State region) and municipal . It shows evidence that this governance structure has contributed to gradually bring intersectoriality into practice in public policy implementation. It concludes on the relevance of the combination of four aspects for committee maturation: i) institutionality through laws and norms; ii) political agenda priority; iii) members engagement; and iv) maintaining meetings rhythm.
\end{abstract} Keywords: Early childhood. Governance. Intersectoriality. Implementation. Committees.
A RBAVAL apoia os esforços relativos à visibilidade dos autores negros na produção científica. Assim, nossas publicações solicitam a autodeclaração de cor/etnia dos autores dos textos para tornar visível tal informação nos artigos.

Recebido: Outubro 23, 2020

Aceito: Novembro 16, 2020

*Autor correspondente:

Cristina Kiomi Mori

E-mail: kikimori@gmail.com

\section{(cc) BY}

Este é um artigo publicado em acesso aberto (Open Access) sob a licença

Creative Commons Attribution, que permite uso, distribuição e reprodução em qualquer meio, sem restrições desde que o trabalho original seja corretamente citado. 


\section{Introdução e método}

Apresentam-se neste texto achados preliminares sobre a constituição dos Comitês Intersetoriais da Política Integrada para a Primeira Infância nas diversas esferas governamentais brasileiras. Os comitês são a principal estratégia de governança definida para a implementação do Marco Legal da Primeira Infância (Lei Federal n. 13.257, 2016) (Brasil, 2016a). Esta estratégia visa promover a integração entre as políticas setoriais e, desta forma, efetivar uma política pública de atenção integral e integrada ao desenvolvimento infantil. O foco do estudo, conduzido sob a forma de uma investigação apreciativa, foram boas práticas e desafios comumente enfrentados na trajetória de amadurecimento dos comitês, a partir de análise documental e entrevistas realizadas com membros de comitês de quatro diferentes instâncias: federal, estadual, regional (região do estado) e municipal.

A primeira infância é o período compreendido entre o nascimento da criança até os 6 anos de idade. Estudos em diversos campos, tais como a psicologia, a sociologia, a pedagogia, a pediatria, a comunicação e, mais recentemente, a neurociência e a economia, têm demonstrado a relevância e impacto que as interações sociais deste período possuem em toda a trajetória da vida de uma pessoa (Guedes, 2020).

Do início da década de 2010 em diante, a agenda da primeira infância ganhou crescente importância no âmbito das políticas públicas no Brasil e em outros países (Diálogo Interamericano \& Fundação Maria Cecília Souto Vidigal, 2020). As políticas públicas voltadas à primeira infância visam apoiar o desenvolvimento integral e integrado das crianças. Integral porque envolve aspectos físicos, psicológicos, intelectuais e sociais (Guedes, 2020). Integrado pois as múltiplas dimensões do desenvolvimento devem ser observadas de maneira global, e não apenas pelo viés de uma especialidade.

Os estudos sobre primeira infância demonstram que é ainda mais relevante para o desenvolvimento infantil o período do nascimento até os 3 anos de idade (Cypel, 2011). Por isso, a organização da sociedade civil Fundação Maria Cecília Souto Vidigal utiliza o termo "primeiríssima infância" para se referir a este período específico e apoiar programas e políticas públicas voltados a esta faixa etária (Marino \& Pluciennik, 2015)1.

No contexto do presente estudo, a intersetorialidade em políticas públicas (Marcondes et al., 2018) consiste sobretudo na articulação entre os diferentes setores que de algum modo operam na solução de um problema público. A estratégia visa superar a fragmentação da atuação entre esses atores para otimizar recursos, aumentar a efetividade das ações e também sua eficácia. Mostra-se necessária em problemas complexos, em que múltiplas causas e dimensões se fazem presentes, e nos quais o contexto específico do território representa um importante fator de influência². Estabelecer a intersetorialidade na prática, contudo, esbarra em limites. É comum existir dificuldade de diálogo entre atores e de substituição de práticas arraigadas, decorrentes da própria especialização de cada setor.

Já os estudos apreciativos (Cooperrider \& Srivastiva, vários, como citados em Bushe, 2012) procuram avançar a partir da investigação dos sucessos obtidos pelas organizações no alcance de seus objetivos. O foco de tais estudos é aquilo que deu certo e está funcionando. A lógica por trás deste tipo de investigação é promover uma reflexão nos sujeitos da ação, e trabalhar em direção àquilo que se deseja a partir de pequenos sucessos. Neste sentido, as organizações são "mistérios a ser apreciados" e o interesse está naquilo que gera vida no sistema, não nos problemas.

O presente estudo, realizado entre setembro e outubro de 2019, passou por três etapas principais: i) análise documental da constituição dos comitês, com base nos documentos legais;

\footnotetext{
${ }^{1}$ No presente estudo, apenas o comitê de âmbito regional nasce de um programa voltado à primeiríssima infância, apresentado no item "Institucionalidade, trajetória e perfil dos comitês". Os demais comitês são instituídos com foco no desenvolvimento da primeira infância como um todo.

2 Como mostram Marcondes et al. (2018), a constituição de comitês intersetoriais é uma estratégia experienciada por um conjunto expressivo de políticas públicas no Brasil, em especial no campo social, na tentativa de superar os desafios da atuação integrada. Cabe destacar que os comitês de políticas e programas específicos não visam substituir conselhos setoriais de quaisquer esferas, tais como o Conselho Nacional de Assistência Social (CNAS), o Conselho Nacional de Saúde (CNS), ou os conselhos municipais e estaduais das políticas setoriais.
} 
ii) comparação da realidade dos comitês instituídos com o que o Marco Legal da Primeira Infância sugere, a partir da análise documental; e iii) entrevistas apreciativas com integrantes de 4 (quatro) diferentes comitês, sob olhar apreciativo e de superação dos desafios. Foram entrevistadas ao menos 2 (duas) pessoas detentoras de informações sobre a trajetória e atuação de cada comitê, sendo ao menos 1 (uma) delas integrante com participação direta no colegiado. Os comitês estudados foram:

a) Comitê Gestor do Programa Criança Feliz do Governo Federal;

b) Comitê Gestor Estadual do Programa Criança Feliz do estado de São Paulo;

c) Comitê Regional do Programa São Paulo pela Primeiríssima Infância da Região de Jundiaí (SP), composto originalmente por 9 (nove) municípios que constituíam a região de Saúde, e ainda integrado por 7 (sete) deles no momento do estudo; e

d) Comitê Gestor Intersetorial da Política Integrada pela Primeira Infância do Município de São Paulo, e respectivo Grupo Técnico.

As entrevistas permitiram uma compreensão ampliada da realidade dos comitês, complementando a análise documental e subsidiando uma comparação mais substantiva entre a previsão legal e a prática da intersetorialidade nas ações dos comitês declaradas pelos entrevistados.

\section{Principais achados}

Os Comitês estudados se mostraram espaços importantes para a promoção da intersetorialidade nas políticas públicas para o desenvolvimento da primeira infância, mesmo aqueles que focam em um programa específico. Ainda que atuem em esferas governamentais diferentes, todos os comitês analisados trouxeram como principal desafio um aspecto comum: promover a intersetorialidade "na ponta", entre as equipes que realizam os atendimentos às crianças e suas famílias.

Considerando a estrutura de governança federativa, observa-se que a intersetorialidade vai se tornando mais tangível quanto mais perto da "ponta" está o comitê. Independentemente da instância federativa, as ações dos comitês e sua repercussão junto aos gestores das políticas públicas são importantes para conferir diretrizes integradas e condições efetivas à atuação finalística intersetorial, tais como prioridade, orçamento e desenvolvimento de equipes.

Em relação a seu funcionamento, a abordagem intersetorial dentro dos comitês parece amadurecer em ciclos sucessivos de reconhecimento mútuo, promoção de ações intersetoriais, reflexão e aprendizagem, e aperfeiçoamento a partir do reconhecimento de novos desafios, conforme as ações são executadas, conforme ilustra a Figura 1.

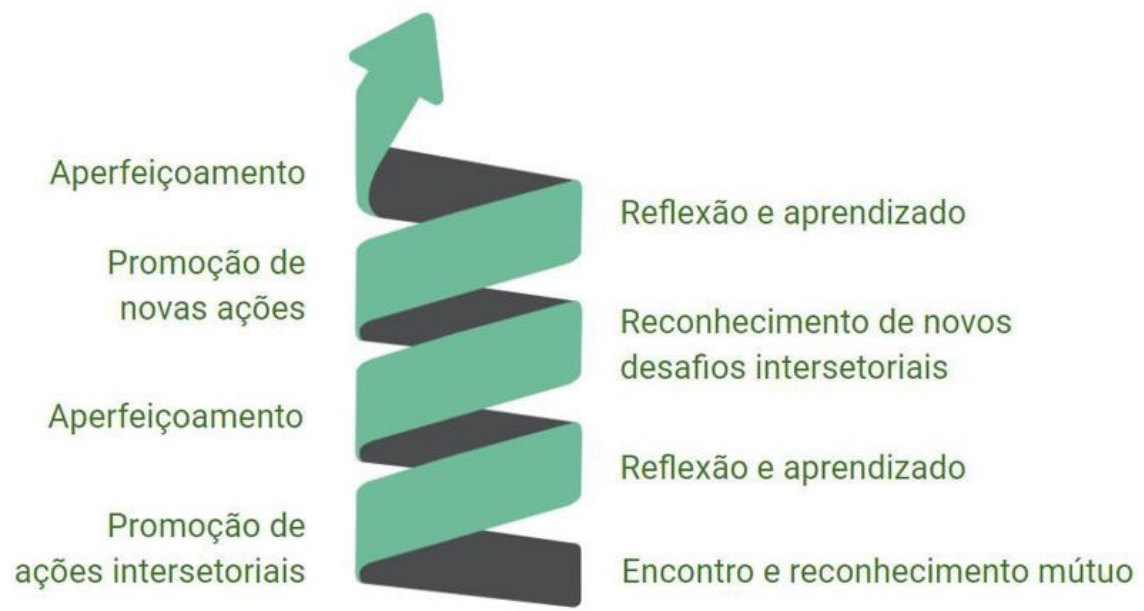

Figura 1. Ciclo de amadurecimento dos comitês.

Fonte: elaboração própria. 
Um comitê ativo consiste em um espaço de encontro periódico e permanente, que permite ao ciclo rodar diversas vezes, com crescente ganhos de amadurecimento da visão intersetorial que aos poucos se desdobram em ações cada vez mais incidentes na ponta. Conforme os comitês realizam essas ações conjuntas, novos elementos e desafios intersetoriais emergem, oferecendo aos membros do comitê oportunidades de reflexão e aprendizado que podem levar ao aperfeiçoamento das ações e crescente sinergia.

Todos os comitês desenvolvem estratégias para propiciar esta visão intersetorial entre os membros. Resumidamente, consistem em promover:

a. Participação conjunta em oficinas, cursos e seminários sobre o tema;

b. Atividades que demandam elaboração conjunta, tais como:

i. Diagnósticos e planos;

ii. Eventos (pequenos, médios e grandes, abertos e fechados);

iii. Visitas a campo;

iv. Guias e materiais formativos para gestores e equipes da ponta.

Tais estratégias permitem a constante troca de boas práticas e conhecimentos sobre desenvolvimento da primeira infância. A realização de atividades conjuntas pelos comitês parece, ao longo do tempo, contribuir para amadurecer não apenas um olhar intersetorial, mas também um sentimento de colaboração entre os membros, ampliando continuamente a percepção de que o trabalho conjunto gera resultados. Neste sentido, a governança prevista no Marco Legal da Primeira Infância parece alcançar os resultados pretendidos: promover a intersetorialidade na prática.

\section{Institucionalidade, trajetória e perfil dos comitês}

O Marco Legal da Primeira Infância é a Lei Federal n. 13.257, de 8 de março de 2016, que:

Dispõe sobre as políticas públicas para a primeira infância e altera a Lei n 8.069 , de 13 de julho de 1990 (Estatuto da Criança e do Adolescente), o Decreto-Lei n 3.689, de 3 de outubro de 1941 (Código de Processo Penal), a Consolidação das Leis do Trabalho (CLT), aprovada pelo Decreto-Lei ${ }^{\circ} 5.452$, de $1^{\circ}$ de maio de 1943, a Lei $n^{\circ} 11.770$, de 9 de setembro de 2008, e a Lei no 12.662, de 5 de junho de 2012. (Brasil, 2016a)

Além de explicitar no arcabouço jurídico do país as especificidades da primeira infância, a lei buscou prever em seu texto a abordagem intersetorial na formulação e implementação de políticas públicas voltadas ao desenvolvimento integral e integrado das crianças de 0 a 6 anos (Diálogo Interamericano \& Fundação Maria Cecília Souto Vidigal, 2020, p. 4). A governança intersetorial foi assim prevista na legislação:

Art. $6^{\circ}$ A Política Nacional Integrada para a primeira infância será formulada e implementada mediante abordagem e coordenação intersetorial que articule as diversas políticas setoriais a partir de uma visão abrangente de todos os direitos da criança na primeira infância.

Art. $7^{\circ} \mathrm{A}$ União, os Estados, o Distrito Federal e os Municípios poderão instituir, nos respectivos âmbitos, comitê intersetorial de políticas públicas para a primeira infância com a finalidade de assegurar a articulação das ações voltadas à proteção e à promoção dos direitos da criança, garantida a participação social por meio dos conselhos de direitos.

$\S 1^{\circ}$ Caberá ao Poder Executivo no âmbito da União, dos Estados, do Distrito Federal e dos Municípios indicar o órgão responsável pela coordenação do comitê intersetorial previsto no caput deste artigo. 
$\S 2^{\circ} \mathrm{O}$ órgão indicado pela União nos termos do $\S 1^{\circ}$ deste artigo manterá permanente articulação com as instâncias de coordenação das ações estaduais, distrital e municipais de atenção à criança na primeira infância, visando à complementaridade das ações e ao cumprimento do dever do Estado na garantia dos direitos da criança. (Brasil, 2016a).

Cada um dos comitês estudados possui institucionalidade, trajetória e perfil distinto, dialogando em maior ou menor grau com o Marco Legal. O Governo Federal instituiu em 2017, por decreto (Decreto de 7 de março de 2017) (Brasil, 2017), o comitê intersetorial previsto no Marco Legal. Este comitê não chegou a se tornar ativo. Os representantes indicados pelos órgãos que o compunham não chegaram a ser nomeados até abril de 2019, momento em que todos os órgãos colegiados instituídos por decreto foram extintos pelo Decreto № 9.759 (Brasil, 2019b).

Em paralelo, foi instituído em âmbito federal o Programa Criança Feliz, em outubro de 2016, com respectivo comitê gestor (Decreto No 8.869, 2016) (Brasil, 2016b). Este se manteve ativo desde então, tendo sua composição revista em 2018 (Decreto No 9.579, 2018) (Brasil, 2018). Também objeto de extinção em abril de 2019, o Comitê Gestor do Programa Criança Feliz trabalhou ativamente para ser reinstituído, o que ocorreu em junho de 2019 (Decreto № 9.855 , 2019) (Brasil, 2019a), com nova composição.

A preservação da institucionalidade do comitê foi uma pauta importante nos meses de agosto e setembro de 2019, que antecederam o presente estudo. As mudanças de governo trouxeram ainda a necessidade de obtenção da indicação de novos membros em substituição aos originalmente designados e, consequentemente, a necessidade de acolhê-los. Antes disso, o comitê havia produzido conjuntamente materiais com foco na formação de agentes visitadores do programa e realizado visita a campo para acompanhar a realidade de implementação do programa.

No estado de São Paulo, a trajetória do comitê se inicia anteriormente à institucionalização do Marco Legal. Desde 2009, estavam em andamento parcerias entre a Fundação Maria Cecília Souto Vidigal e seis municípios do estado para desenvolvimento de um programa voltado à primeiríssima infância. Em 2013, este programa foi abraçado pelo governo do estado, sendo denominado São Paulo pela Primeiríssima Infância (SPPI), e levado a outros 41 municípios. Ao longo da implementação, percebeu-se a necessidade de constituição de um comitê gestor intersetorial, que estava prestes a ser formalizado quando o governo federal tornou obrigatória a instituição pelos estados de comitês gestores para adesão e recebimento de recursos do Programa Criança Feliz.

Com isso, o comitê do programa SPPI não chegou a ser formalizado. O Comitê Gestor Estadual do Programa Criança Feliz foi instituído em 23 de fevereiro de 2017 (Decreto estadual No 62.492, 2017) (São Paulo, 2017a), e se mantém ativo desde então. Em setembro de 2019, momento de realização deste estudo, os integrantes do comitê haviam recém aprovado a transformação do colegiado no Comitê Estadual Intersetorial da Política de Primeira Infância, para abranger também outros programas, como o SPPI. Outra pauta recente do comitê havia sido a atualização da matriz de ações de cada um dos órgãos integrantes para correspondente atualização do Plano Estadual do programa.

O comitê da Região de Jundiaí (SP) foi instituído a partir da estratégia de governança de um programa, sem um instrumento jurídico que determinasse sua existência e funcionamento, e se mantém ativo desde 2012. A trajetória deste comitê remonta a 2009, quando Itupeva consistia em um dos seis municípios que haviam estabelecido parceria junto à Fundação Maria Cecília Souto Vidigal para o desenvolvimento de políticas voltadas à primeiríssima infância. Em 2011, Itupeva compartilhou sua experiência junto aos então nove municípios que compunham o Colegiado de Gestão Regional de Saúde de Jundiaí e estes se interessaram em também desenvolver o programa.

Composto por representantes de todos os municípios integrantes da região de saúde (originalmente nove e, no momento do estudo, sete), o comitê contou com o papel fundamental de articulação desempenhado pela servidora Lígia Bestetti, vinculada à regional da Secretaria de Saúde do estado. Os resultados positivos do comitê regional de Jundiaí foram importantes 
para a institucionalização do programa SPPI no estado de São Paulo. Anterior ao Criança Feliz, o SPPI é coordenado pela Secretaria Estadual de Saúde e também tem como proposta o desenvolvimento infantil integral e integrado. Ainda que focado no programa, o comitê regional de Jundiaí se mostra uma importante instância de promoção da intersetorialidade para as políticas de primeira infância. Sua atuação fortalece os comitês municipais da região, de composição intersetorial.

As pautas do comitê regional no momento do estudo incluíam a avaliação da Semana do Bebê realizada nos municípios da região, a promoção de atividades conjuntas de formação e a constante troca de boas práticas. Além disso, o comitê estava buscando a inclusão de ações intersetoriais para a primeira infância nos Planos Plurianuais de Aplicação (PPA) dos municípios. Já os dois municípios que haviam deixado de integrar a região de saúde de Jundiaí e passado a integrar a de Campinas estavam levando para a nova região a proposta de constituição de um comitê nos mesmos moldes.

Diferentemente dos demais comitês analisados, o Município de São Paulo instituiu em 2018, e mantém ativo desde então, um Comitê Gestor Intersetorial da Política de Primeira Infância, apoiado por um Grupo Técnico e uma Comissão de Avaliação, além de Comitês Regionais. Todas essas instâncias possuem atribuição de integrar múltiplos programas que influenciam o desenvolvimento da primeira infância. A trajetória deste comitê remonta ao início de 2017, quando um grupo intersetorial ainda não instituído formalmente atuava na elaboração de um plano de ação para a primeira infância no município. A coordenação do grupo foi atribuída à Secretaria de Governo, diante da percepção de que a agenda intersetorial demandava articulação por uma secretaria não finalística e central na gestão³.

O grupo promoveu a realização de um diagnóstico de indicadores de primeira infância do município, além de audiências públicas e escutas junto às redes de saúde, assistência e educação, e às crianças. Com a intenção de conferir maior robustez institucional, a política municipal foi instituída por lei (Lei Municipal № 16.710, 2017) (São Paulo, 2017b), que tornou obrigatório ao Poder Executivo elaborar um Plano Municipal para o desenvolvimento da Primeira Infância, Planos de Ação a cada gestão, um Comitê Gestor formado por Secretários e a criação de Comitês Regionais no município. Uma resolução do Comitê Gestor (Resolução SGM/CGIPMIPI N 2, 2019) (São Paulo, 2019b) oficializou o Grupo Técnico, instância de governança que se reúne com maior frequência, além de uma comissão de avaliação. $O$ Comitê Gestor foi instituído em junho de 2018 (Decreto Municipal № 58.294, 2018) (São Paulo, 2018) e se reúne quando as deliberações demandam decisão pelo nível superior de gestão. Por meio de resolução, o Comitê Gestor instituiu 32 comitês regionais em fevereiro de 2019 (Resolução SGM/ CGIPMIPI No 1, 2019) (São Paulo, 2019a).

Entre as pautas recentes do Grupo Técnico e do Comitê Gestor em setembro de 2019 (momento de realização deste estudo), haviam sido tratados os critérios para implementação dos comitês regionais e se encontravam em andamento discussões sobre a integração das bases de dados das políticas de Saúde, Educação e Assistência Social, e o desenvolvimento de um protocolo integrado de atendimento entre as três áreas, em diálogo com comitês regionais. Cabe destacar que os comitês regionais foram incorporados à governança por sugestão da Secretaria de Assistência e Desenvolvimento Social, em função da previsão deste tipo de instância no Programa Criança Feliz. Os Conselhos Tutelares são convidados a participar das reuniões destes comitês.

Após conhecer cada comitê, foi possível desenhar um quadro geral do perfil e composição de cada comitê estudado (Diagrama 1). O quadro apresenta cada comitê por esfera, indicando na respectiva linha de cada coluna: i) sua abrangência de atuação (se toda a política para a primeira infância ou se circunscrita a um programa específico); ii) o tipo de normativo que o instituiu; iii) se o comitê estava ativo no momento de realização do estudo; e iv) a periodicidade de suas reuniões, além dos órgãos e instituições que o compunham, iniciando pelo órgão coordenador. No caso do comitê Regional, havia previsão da coordenação executiva ser rotativa entre os municípios integrantes.

\footnotetext{
3 Na gestão anterior, entre 2013 e 2016, a Prefeitura do Município de São Paulo havia desenvolvido o programa São Paulo Carinhosa, envolvendo 14 secretarias municipais com atuação relacionada à primeira infância em ações dirigidas a territórios vulneráveis.
} 


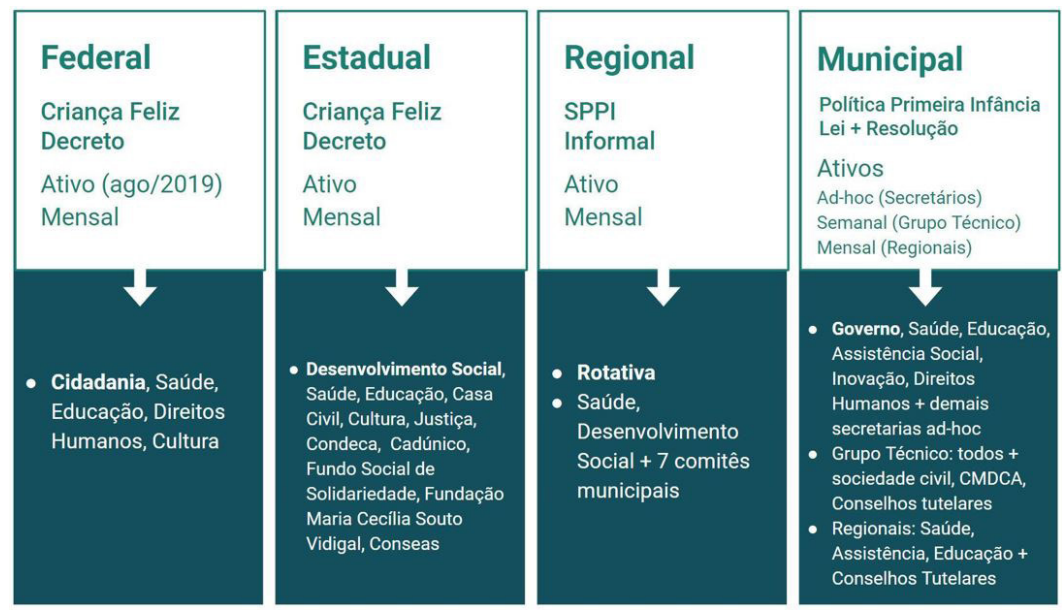

Diagrama 1. Perfil e composição dos comitês.

Fonte: elaboração própria.

As diferentes trajetórias de constituição e funcionamento se refletem em níveis de maturidade distintos entre os comitês. A manutenção das atividades desde 2011, por exemplo, na Região de Jundiaí permitiu que este comitê percorresse diversas vezes o ciclo de amadurecimento apresentado na Figura 1, independentemente da institucionalização por normativo e superando ativamente as inúmeras mudanças de gestão nos municípios ao longo dos anos. As estratégias utilizadas para obter esta perenidade são apresentadas mais adiante, no item "Boas práticas".

O estudo também demonstrou que todos os comitês estudados contam com a efetiva participação dos membros formalmente designados, exceto os que preveem participação da Secretaria Estadual de Educação. Esta parece não se sentir integrada à temática, muitas vezes compreendida apenas como objeto da Educação Infantil e, portanto, responsabilidade dos municípios. Contudo, há temas relacionados ao desenvolvimento da primeira infância (ex.: gravidez na adolescência) que demandam o engajamento das escolas de ensino fundamental e médio, sob responsabilidade estadual. O engajamento da Secretaria Estadual de Educação se mostra um desafio tanto no comitê Estadual como no da Região de Jundiaí.

À exceção destes casos, os membros apresentam engajamento nos processos de planejamento, deliberação e encaminhamento de ações. A maioria das decisões tomadas flui por meio dos próprios integrantes a partir das reuniões. Isso significa que os comitês não esperam anuência ou deliberações das instâncias superiores para atuarem intersetorialmente. A maior parte das ações que empreendem estão dentro dos próprios limites discricionários das pessoas que compõem o comitê, o que é um bom indicador de que o espaço é utilizado para gerar e aproveitar oportunidades de integração de esforços.

\section{O amadurecimento da intersetorialidade rumo à "ponta"}

O ciclo de amadurecimento da visão intersetorial dos comitês, apresentado na Figura 1, se torna mais visível quando se olha para as trajetórias dos comitês. O primeiro momento, de encontro e reconhecimento mútuo, demanda um alinhamento sobre o próprio papel do colegiado. Na maioria dos casos, este primeiro reconhecimento mútuo se inicia nas reuniões regulares do comitê. Em alguns casos, oficinas e atividades de planejamento são espaços importantes para aprofundar e acelerar esta troca. Em outros, atividades de formação conjuntas permitem aprofundar a visão intersetorial. A organização de eventos como a Semana do Bebê ou a Semana Mundial do Brincar também se mostram como boas oportunidades para reconhecimento mútuo, por meio de uma ação conjunta de horizonte temporal definido.

"Saber o que o outro faz na prática" é o primeiro passo para o conjunto de atores perceber oportunidades de otimização de esforços. O objetivo pode estar tanto em promover um cuidado mais integral à criança e a sua família pelas equipes que realizam atendimentos ("na 
ponta") como em articular e dar visibilidade à importância da primeira infância para lideranças políticas e sociedade como um todo, no caso dos eventos.

Conforme os atores se conhecem e se reconhecem mutuamente, passam a identificar possibilidades concretas de colaboração. Surgem as primeiras ideias do que pode ser mudado na atuação de cada setor para um atendimento integral e integrado à infância. Os comitês passam então a elaborar estratégias para promover a atuação desejada. Cada passo neste caminho permite aprofundar o conhecimento sobre os procedimentos de cada setor e construir conjuntamente novas formas de atuar.

O passo seguinte é a implementação das estratégias conjuntas e o ciclo se nutre a partir da reflexão sobre a implementação, com a busca por aprendizados que permitam ajustes e melhorias na abordagem. A conclusão deste ciclo, nos casos estudados, parece ter trazido à tona novos desafios e demandas para a intersetorialidade. Nos comitês ativos há mais tempo, o ambiente para desenvolver o novo ciclo é favorecido pelo vínculo criado entre os membros a partir da experiência anterior. A confiança estabelecida no fazer conjunto propicia criatividade e engajamento, num ciclo virtuoso. As boas práticas que levam a este amadurecimento são apresentadas no item 2.3, a seguir neste estudo.

Os Comitês são o principal espaço de discussão e promoção de intersetorialidade da política de Primeira Infância em seus contextos. Possuem forte engajamento de seus membros (exceto da Secretaria Estadual de Educação), com maior robustez institucional e política no Município de São Paulo. Na Região de Jundiaí, o caráter regional confere muita força à iniciativa e ajuda a manter os comitês dos municípios ativos, sustentando a implementação do Programa SPPI a partir da formulação e execução contínua de ações práticas.

Há evidências de que esta estrutura de governança, baseada na atuação dos comitês, gera reflexos "na ponta". O Comitê Federal do Criança Feliz formulou e publicou materiais para apoio à formação de agentes visitadores, englobando cultura, saúde, cidadania e educação. O colegiado propiciou também a incorporação de ações da Cultura nos territórios, tais como um guia com brincadeiras tradicionais e a sugestão de atividades de leitura em equipamentos públicos intersetoriais, como as Praças CEU.

Outra evidência é a ampliação da percepção da sociedade e, principalmente, das lideranças políticas sobre a agenda da primeira infância, a partir de eventos realizados anualmente na Região de Jundiaí, como a Semana do Bebê e Semana Mundial do Brincar. O comitê relata que nenhum prefeito quer "ficar de fora" das iniciativas. É também lá que crescentemente tem se ampliado a percepção de profissionais sobre a necessidade de atuação complementar entre equipes das diferentes secretarias, sobretudo quando participam de atividades de formação conjuntas. Neste mesmo sentido, no município de São Paulo se inicia um piloto para integração de protocolos de atendimento com participação dos comitês regionais municipais.

A experiência de comitês no âmbito do SPPI possibilitou que creches passassem, por exemplo, a aceitar oferecer às crianças leite materno trazido pelas mães. Em Ilhabela (SP), as discussões no âmbito do comitê local do SPPI no município gerou uma conversa com os dois principais empregadores da ilha para liberar pais e mães para participarem das reuniões nas creches e escolas municipais.

A trajetória dos comitês também aponta um possível percurso para que a intersetorialidade seja cada vez mais uma realidade no território, conforme apresentado no Diagrama 2. Este diagrama foi concebido a partir das experiências relatadas pelos integrantes dos comitês estudados e da compreensão das autoras sobre a dinâmica das políticas públicas no território a partir de suas experiências profissionais e da literatura.

O primeiro passo percebido nas experiências estudadas foi o de sensibilizar quem ocupa o cargo político máximo em relação à prioridade da agenda da Primeira Infância e sobre a importância de um comitê que efetive o caráter intersetorial das políticas neste tema. Nos casos de existência prévia de comitês intersetoriais de programas específicos, um segundo passo observado, em especial na experiência estadual estudada, foi a busca por convergir as discussões para um comitê em que o conjunto das políticas voltadas ao desenvolvimento da Primeira Infância possam dialogar. 


\begin{tabular}{|c|c|c|c|c|c|}
\hline $\begin{array}{l}\text { Sensibilizar } \\
\text { prefeitos } \\
\text { para } \\
\text { priorização } \\
\text { da primeira } \\
\text { infância e } \\
\text { criação de } \\
\text { comitês } \\
\text { municipais }\end{array}$ & $\begin{array}{l}\text { Apoiar a } \\
\text { integração } \\
\text { de comitês } \\
\text { intersetoriais } \\
\text { instituídos } \\
\text { para cada } \\
\text { programa em } \\
\text { Comitês da } \\
\text { Política para } \\
\text { Primeira } \\
\text { Infância }\end{array}$ & $\begin{array}{l}\text { Apoiar a } \\
\text { elaboração } \\
\text { de planos } \\
\text { municipais } \\
\text { para dar } \\
\text { concretude } \\
\text { às ações }\end{array}$ & $\begin{array}{l}\text { Integrar } \\
\text { bases de } \\
\text { dados } \\
\text { setoriais para } \\
\text { melhor } \\
\text { diagnóstico e } \\
\text { intervenção }\end{array}$ & $\begin{array}{l}\text { Formalizar o } \\
\text { atendimento } \\
\text { em rede, } \\
\text { sobretudo } \\
\text { em grandes } \\
\text { centros } \\
\text { urbanos e } \\
\text { metrópoles }\end{array}$ & $\begin{array}{l}\text { Apoiar a } \\
\text { formação } \\
\text { intersetorial de } \\
\text { equipes de } \\
\text { atendimento }\end{array}$ \\
\hline
\end{tabular}

Diagrama 2. Possível percurso para a atuação dos comitês alcançar "a ponta".

Fonte: elaboração própria.

Um terceiro passo que se mostrou presente nas experiências foi o comitê se constituir como o locus institucional coordenador da elaboração de um plano com ações concretas no tema na instância governamental correspondente. O grau de abrangência, complexidade e intersetorialidade deste plano pode amadurecer continuamente caso o comitê se disponha a realizar a efetiva gestão do plano, acompanhando e avaliando sua execução periodicamente.

O quarto passo notado especialmente na experiência municipal foi a necessidade de integrar as bases de dados sobre as políticas públicas que impactam as crianças de 0 a 6 anos para ampliar a sinergia e otimizar as ações voltadas ao seu desenvolvimento. Mostra-se um aspecto fundamental para o acompanhamento integrado do conjunto de interfaces do poder público com as crianças e suas famílias no território.

O quinto passo, observado também apenas na experiência municipal, consistiu na busca pela formalização da atuação efetivamente em rede das políticas públicas no que tange o atendimento às crianças e suas famílias. Isso significa a integração dos serviços das políticas públicas setoriais, em especial saúde, educação e assistência social, com procedimentos que permitam referenciar crianças e famílias de uma política para a outra, a partir de protocolos pactuados entre elas.

Por fim, percebe-se a necessidade de formação intersetorial das equipes para este atendimento integrado, aspecto observado tanto na experiência municipal como na regional. A formação conjunta de profissionais das distintas políticas setoriais contribui para que reconheçam-se uns aos outros como sujeitos e à criança como centro da atuação de todos. Desta forma, a integração prevista nos protocolos parece ampliar seu potencial, de modo a se efetivar de maneira mais orgânica.

\section{Síntese de boas práticas}

Os achados mais interessantes deste estudo são as boas práticas colhidas na trajetória e atuação de cada comitê, que podem servir de inspiração a outros comitês e também aos próprios comitês estudados. O olhar apreciativo gera oportunidades de celebração, nutrindo uma visão positiva e de amadurecimento a partir de pequenos sucessos.

a) Gerais

Dentre as práticas presentes no conjunto dos comitês estudados, destaca-se inicialmente a definição compartilhada do o propósito do comitê, com apoio de oficinas, cursos, seminários sobre desenvolvimento da primeira infância e intersetorialidade, com participação de todas as secretarias. Estas atividades permitem o reconhecimento mútuo dos integrantes do comitê, de seus saberes prévios e de novas informações sobre o tema, e a exploração coletiva daquilo que une o grupo: o foco em políticas de desenvolvimento da primeira infância. Neste sentido, é possível iniciar o diálogo intersetorial a partir do comitê existente, mesmo que seja 
de um único programa, que pode ir ganhando um olhar mais abrangente à medida que a compreensão do desenvolvimento integral e integrado se expande nas trocas e reflexões.

Outra prática que se mostra frutífera é "sair da mesa" e conhecer o território. Esta ação se mostrou especialmente importante nos comitês das instâncias federativas mais distantes do território (federal, estadual), mas foram valorizadas mesmo nos comitês regional e municipal, pois gestores das políticas públicas (sobretudo em municípios do tamanho de São Paulo, experiência aqui estudada) costumam perder o contato diário com o que acontece concretamente nas unidades de atendimento ou nos locais onde moram as crianças, em especial as mais vulneráveis.

A prática de executar ações concretas em conjunto entre os órgãos que compõem o comitê também é uma lição aprendida neste processo. Realizar eventos e mesmo elaborar materiais de formação em conjunto são atividades "mão na massa" que contribuem para estreitar laços entre integrantes do comitê, além de conferir senso de realização ao grupo e ampliar o engajamento com a causa a partir dos resultados observados. 0 processo de reflexão, avaliação e aprendizagem contínua das ações colocadas no mundo tem grande potencial para o amadurecimento tanto da intersetorialidade como da qualidade das políticas implementadas.

\section{b) Comitê Estadual}

Dentre as boas práticas colhidas junto ao Comitê Estadual, destaca-se primeiramente a realização de reuniões em sistema de rodízio entre os órgãos integrantes do colegiado. A cada mês uma Secretaria anfitria a reunião do comitê, conferindo senso de pertencimento e responsabilidade a todas.

Este colegiado também estabeleceu um regimento interno para garantir presença dos membros titulares nas reuniões e, desta forma, preservar a seriedade e comprometimento dos órgãos integrantes. As regras neste sentido incluem a necessidade de justificar eventuais ausências em reuniões marcadas e a substituição do membro que se ausente por certo número de reuniões de maneira injustificada.

Também do Comitê Estadual vem uma boa prática de elaboração inicial de um plano para o desenvolvimento da primeira infância, com as seguintes etapas:

i. Diagnóstico da situação da primeira infância em todo o estado, com base em dados e indicadores sempre que existentes;

ii. Diagnóstico territorial, destacando diferenças nos indicadores entre regiões, de modo a evidenciar os desafios decorrentes de desigualdades socioeconômicas e outros aspectos potencializadores de vulnerabilidades;

iii. Matriz intersetorial, composta pelas ações de cada secretaria no tema do desenvolvimento da primeira infância e a intenção de, no futuro próximo, maepar, suas interfaces com as ações das outras secretarias;

iv. Planejamento do monitoramento das ações, com uma sistemática de acompanhamento da execução que permita reflexões periódicas e compartilhamento de resultados, visando otimizar processos e promover sinergias.

O Comitê Estadual também promoveu ações como a produção de material de orientação aos municípios para instituírem seus comitês municipais de primeira infância (com e sem apoio do Prefeito). Promoveu ainda que Agentes Comunitários de Saúde e Visitadores do Criança Feliz pudessem se reunir para entenderem seus papéis, dado que são dois agentes de políticas públicas que realizam visitas ao domicílio das famílias. Estes encontros se mostram fundamentais para que cada um dos agentes compreenda o papel e responsabilidades de seu par, e aquilo que um pode fazer para apoiar o outro. Além disso, a coordenação destas visitas ajuda a evitar a sobrecarga das famílias em relação à presença domiciliar de agentes de políticas públicas e esclarecer também a elas o papel de cada um.

Membros do Comitê Estadual promoveram ainda diálogo técnico com parlamentares interessados em propor Projeto de Lei para primeira infância, buscando assim a priorização 
política da pauta. Neste mesmo sentido de "advocacy" pela causa, estavam realizando articulação com financiadores privados para atualização do índice de desenvolvimento de primeira infância do estado.

Por fim, trouxe uma boa prática de engajamento para a rede. Em um vídeo curto, divulgado por redes sociais, a. Secretária de Desenvolvimento Social do estado parabenizou as equipes do Criança Feliz no momento em que o programa recebeu o prêmio internacional Wise Awards em 2019.

c) Comitê Regional de Jundiaí

As boas práticas apresentadas pelo Comitê da Região de Jundiaí estão bastante relacionadas ao modo de funcionamento de um comitê regional. A primeira diz respeito à composição do comitê: representantes dos 7 municípios, sendo 1 articulador e 1 representante de cada secretaria (ao menos saúde, assistência e educação). Além disso, as reuniões são anfitriadas por um dos municípios membro a cada mês, em sistema de rodízio. No mesmo dia da reunião, é marcada uma agenda do comitê regional com Prefeito e/ou Secretário(s) do município anfitrião, de modo a mantê-los engajados no tema da primeira infância e, eventualmente, buscar soluções para questões que pontualmente estejam sendo obstáculos às ações foco do comitê. .

O aspecto afetivo e celebrativo é bastante peculiar neste comitê regional, trazendo práticas que podem ser muito interessantes também em outros contextos. Cada reunião possui em sua agenda a apresentação, pelo município anfitrião, de uma experiência exitosa local no tema do desenvolvimento da primeira infância. Além disso, as reuniões prezam pelo acolhimento, aprendizado e atratividade. Os municípios buscam locais diferentes para a realização das reuniões (ex.: no zoológico municipal), o que é considerado um ponto positivo para o engajamento do grupo.

Também peculiar a esta experiência de comitê é o perfil da articuladora regional, servidora estatutária da Secretaria Estadual de Saúde na região. Sua atuação engaja permanentemente o grupo e ela participa não apenas das reuniões do comitê regional, mas também sempre que pode de reuniões dos comitês municipais, alternando os municípios (está na reunião de um município diferente por mês).

Neste comitê se observa ainda uma prática facilmente aplicável em outros contextos que é o mapeamento das ações de cada Secretaria com ações voltadas ao desenvolvimento da primeira infância para início de construção de Planos Municipais.

Realiza-se também uma oficina de apoio técnico ao final de cada ano, cuja programação inclui:

i. Feira de boas práticas: cada município apresenta suas melhores práticas no desenvolvimento da primeira infância para que os demais "comprem" essas ideias. O compromisso é que os municípios apliquem no ano seguinte as boas práticas que "compraram" na feira, apresentando o andamento e os resultados no comitê;

ii. Atualização sobre as novas pesquisas e descobertas a respeito do desenvolvimento da primeira infância, o que é visto como oportunidade de aprendizado para os integrantes do comitê e valorizado pela possibilidade de estar em contato com os debates mais recentes da agenda;

iii. Balanço da atuação do comitê em relação ao ano que está se encerrando e planejamento do ano seguinte.

Em relação a aç̃̃es de engajamento de dirigentes políticos, o comitê promove um café da manhã com novos prefeitos quando estes assumem seus mandatos, dialogando sobre o tema da primeira infância. Também mantém constante interlocução com secretários e prefeitos dos municípios da região.

Por fim, o comitê realiza eventos conjuntos de caráter regional e também apoia os municípios na realização da Semana do Bebê e da Semana Mundial do Brincar, temas que têm servido para o despertar da sociedade e dos governos em relação à importância do desenvolvimento integral e integrado na primeira infância. 
d) Comitê Municipal de São Paulo

As boas práticas advindas do município de São Paulo estão relacionadas não apenas à existência do comitê gestor em si, mas no arcabouço de governança mais amplo da política.

Observou-se prioridade de governo que se desdobrou em um arcabouço institucional robusto, bem como à incorporação do tema da primeira infância ao Programa de Metas. O município também promoveu um amplo diagnóstico para elaboração de seu Plano Municipal, com base em indicadores.

Com a intenção de ter uma política construída também de baixo para cima, estava implantando e mobilizando comitês regionais nas distintas Subprefeituras da cidade, com representantes das políticas setoriais .

Por fim, o município trouxe duas práticas fundamentais para a intersetorialidade. A primeira delas consiste na integração das bases de dados, necessária para enxergar a criança de maneira integral e integrada e permitir a produção de diagnósticos intersetoriais por região. A segunda, a elaboração de protocolos integrados de atenção à primeira infância em conjunto com comitês regionais, para que a intersetorialidade possa acontecer na prática no atendimento às crianças e suas famílias.

Na experiência do município foi destacado o envolvimento de organizações da sociedade civil com grande expertise no tema da primeira infância (Fundação Maria Cecília Souto Vidigal, Fundação Abrinq, Unicef, Instituto 0 a 6, Bernard van Leer Foundation). Ter a parceria de organizações que já dominam e atuam com o tema em diferentes localidades do país (e em alguns casos do mundo) permite ampliar referências e se apropriar de expertises que o município dificilmente desenvolveria por conta própria.

\section{Desafios e conclusões}

Para iniciar as conclusões deste estudo, trazemos à reflexão os desafios que os comitês estudados encontram em sua atuação. Este conjunto de desafios pode suscitar novos estudos e pesquisas neste campo e contribuir para a evolução de políticas públicas que demandam intersetorialidade.

Um primeiro desafio consiste no diálogo interfederativo entre os próprios comitês e também nos desdobramentos dos programas junto às redes setoriais. Algumas delas já possuem instâncias interfederativas consolidadas, como o SUS e o SUAS, com desafios próprios de promoção da intersetorialidade em diversas agendas, incluindo a de desenvolvimento da primeira infância.

Outro desafio apontado é a necessidade de articulação entre programas que demandam comitês intersetoriais, sobretudo no âmbito dos municípios. A isso se soma a necessidade de fortalecimento da capacidade dos municípios para diagnóstico e planejamento, presente também em outras políticas públicas. Foi trazida ainda a necessidade de integração de outras secretarias além da Saúde, Assistência Social e Educação, tais como a Cultura, nos comitês municipais.

A organização orçamentária é outro aspecto importante. Colocar ao menos uma linha de ação intersetorial para a primeira infância nos Planos Plurianuais de Aplicações e respectivas Leis Orçamentárias consiste em um passo fundamental para oferecer condições materiais à intersetorialidade. O orçamento torna possível a promoção de ações efetivamente conjuntas sem que sejam considerados desvios de finalidade ou perda de recursos por uma ou outra secretaria.

Outro requisito fundamental a ser conquistado é a integração de bases de dados para melhores diagnósticos intersetoriais. Dentro de cada setor, esta integração já é um enorme desafio, tendo em vista a multiplicidade de atores e programas. Intersetorialmente, depurar e integrar bases como, por exemplo, Cadúnico, DataSUS e de gestão das matrículas escolares envolve lidar com sistemas construídos em diferentes plataformas e, em muitos casos, sem uma chave única de identificação que permita o cruzamento de dados. 
No âmbito político, um desafio permanente é a obtenção de reconhecimento e apoio, tanto de secretários como de prefeitos, e a continuidade nas mudanças de mandato. Isso se reflete também em níveis distintos de engajamento entre as secretarias participantes dos comitês.

Sobre as políticas em si, os comitês desejam garantir espaço para boas práticas locais e promover mudanças na prática, transformando a cultura de trabalho das secretarias e equipes. Isso demanda superar obstáculos como as resistências corporativas, a rotatividade de pessoal nas equipes finalísticas e a comunicação da estratégia intersetorial dos comitês até a ponta. Além disso, destaca-se a necessidade de sobrecarregar menos as famílias, otimizando as estratégias de visitação.

O foco principal da estratégia de governança por meio de comitês, conforme previsto no Marco Legal, é amadurecer e efetivar a intersetorialidade. A trajetória dos comitês estudados aponta para a relevância de quatro aspectos fundamentais visando este objetivo:

a) a institucionalidade garantida em leis e normas;

b) a prioridade política dada à agenda da primeira infância;

c) o engajamento dos integrantes do comitê; e

d) a manutenção de um pulso de reuniões que confira ritmo aos encontros.

Em relação a este conjunto de aspectos, é importante destacar que a institucionalidade normativa em parte se justifica pela cultura administrativa do setor público brasileiro, de um Estado garantidor da lei (Longo, 2007, p. 63-66). O estudo trouxe casos em que esta institucionalidade está plenamente presente, como no município de São Paulo, com seu conjunto robusto de normativos. Contudo, trouxe também um caso em que a previsão normativa (Marco Legal Federal) não levou à ativação do correspondente comitê. Estes dois casos apontam que a norma sozinha não consiste em elemento suficiente para colocar a governança para funcionar.

Notadamente no município de São Paulo, a prioridade política dada à agenda da primeira infância foi um fator fundamental, tanto para o estabelecimento dos marcos normativos como para que fossem colocados em prática. Nos municípios da Região de Jundiaí, o esforço do comitê para manter a prioridade política a cada novo prefeito que inicia seu mandato demonstra também a importância deste elemento. O comitê da Região de Jundiaí nos mostra ainda uma experiência que se desenvolve há anos à margem da normatização, mantida sobretudo pelo forte engajamento de integrantes do comitê e um pulso de reuniões constante, com diversas estratégias bem sucedidas de ativação dos membros.

Por tudo isso, parece fazer sentido olhar para esses quatro elementos como importantes e complementares. A combinação de institucionalidade normativa, prioridade política, engajamento dos membros e pulso de reuniões oferece oportunidades para uma curva de aprendizagem e amadurecimento que de fato endereça a demanda por intersetorialidade e cada vez mais a traz como uma realidade para o atendimento às crianças e às famílias.

\section{Fonte de financiamento}

Este estudo foi realizado por demanda e com financiamento da Fundação Maria Cecília Souto Vidigal.

\section{Conflito de interesse}

Não há

\section{Referências}

Brasil. (2016a). Dispõe sobre as políticas públicas para a primeira infância e altera a Lei no 8.069 , de 13 de julho de 1990 (Estatuto da Criança e do Adolescente), o Decreto-Lei n 3.689, de 3 de outubro de 1941 (Código de Processo Penal), a Consolidação das Leis do Trabalho (CLT), aprovada pelo Decreto-Lei ${ }^{\circ}$ 5.452 , de $1^{\circ}$ de maio de 1943 , a Lei ${ }^{\circ} 11.770$, de 9 de setembro de 2008 , e a Lei ${ }^{\circ} 12.662$, de 5 de junho de 2012 (Lei № 13.257, de 8 de março de 2016). Diário Oficial [da] República Federativa do Brasil, Brasília. Recuperado em 30 de setembro de 2019, de http://www.planalto.gov.br/ccivil_03/_Ato2015-2018/2016/ Lei/L13257.htm 
Brasil. (2016b). Institui o Programa Criança Feliz (Decreto n 8.869, de 5 de outubro de 2016). Diário Oficial [da] República Federativa do Brasil, Brasília. Recuperado em 30 de setembro de 2019, de http://www. planalto.gov.br/ccivil_03/_ato2015-2018/2016/Decreto/D8869.htm

Brasil. (2017). Institui o Comitê Intersetorial de Políticas Públicas para a Primeira Infância (Decreto de 7 de março de 2017). Diário Oficial [da] República Federativa do Brasil, Brasília. Recuperado em 30 de setembro de 2019, de http://www.planalto.gov.br/ccivil_03/_ato2015-2018/2017/dsn/Dsn14452.htm

Brasil. (2018). Consolida atos normativos editados pelo Poder Executivo federal que dispõem sobre a temática do lactente, da criança e do adolescente e do aprendiz, e sobre o Conselho Nacional dos Direitos da Criança e do Adolescente, o Fundo Nacional para a Criança e o Adolescente e os programas federais da criança e do adolescente, e dá outras providências (Decreto $n^{\circ} 9.579$, de 22 de novembro de 2018). Diário Oficial [da] República Federativa do Brasil, Brasília. Recuperado em 30 de setembro de 2019, de http://www.planalto.gov.br/ccivil_03/_Ato2015-2018/2018/Decreto/D9579.htm

Brasil. (2019a). Dispõe sobre o Comitê Gestor do Programa Criança Feliz (Decreto n 9.855, de 25 de junho de 2019). Diário Oficial [da] República Federativa do Brasil, Brasília. Recuperado em 30 de setembro de 2019, de http://www.planalto.gov.br/ccivil_03/_Ato2019-2022/2019/Decreto/D9855.htm

Brasil. (2019b). Extingue e estabelece diretrizes, regras e limitações para colegiados da administração pública federal (Decreto n 9.759, de 11 de abril de 2019). Diário Oficial [da] República Federativa do Brasil, Brasília. Recuperado em 30 de setembro de 2019, de http://www.planalto.gov.br/ccivil_03/_ato20192022/2019/decreto/D9759.htm

Bushe, Gervase. (2012). Foundations of Appreciative Inquiry: History, Criticism and Potential. Al Practitioner, 14(1), 8-20.

Cypel, Saul. (Org.) (2011). Fundamentos do desenvolvimento infantil: da gestação aos 3 anos. São Paulo: Fundação Maria Cecília Souto Vidigal. Recuperado em 30 de setembro de 2019, de http:// agendaprimeirainfancia.org.br/arquivos/Fundamentos_do_desenvolvimento\%20infantil.pdf

Diálogo Interamericano, \& Fundação Maria Cecília Souto Vidigal. (2020). Brasil: Informe de progreso de políticas de primeira infancia. Agenda Regional para el Desarollo Integral de la Primera Infancia. Recuperado em 30 de setembro de 2019, de https://www.fmcsv.org.br/pt-BR/biblioteca/brasil-relatorio-progressopoliticas-primeira-infancia/

Guedes, Ana Carolina Vidal. (Org.). (2020). Primeiríssima infância. Interações: comportamentos de pais e cuidadores de crianças de 0 a 3 anos. São Paulo: Fundação Maria Cecilia Souto Vidigal. Recuperado em 30 de setembro de 2019, de https://www.fmcsv.org.br/pt-BR/biblioteca/primeirissima-infancia-interacoescomportamentos-pais-cuidadores-criancas-0-3-anos/

Longo, Francisco. (2007). Mérito e flexibilidade - A gestão de pessoas no setor público. São Paulo: Edições Fundap. pp. 63-66.

Marcondes, Mariana Mazzini, Sandim, Tatiana Lemos, \& Diniz, Ana Paula Rodrigues. (Orgs.). (2018). Transversalidade e intersetorialidade: mapeamento do debate conceitual no cenário brasileiro. Administração Pública e Gestão Social, 10(1), 22-33.

Marino, Eduardo, Harasawa, Ely, \& Pluciennik, Gabriela Aratangy. (Orgs.). (2014). Dez passos para implementar um programa para a primeiríssima infância (Vol. 1, Coleção Primeiríssima Infância). São Paulo: Fundação Maria Cecilia Souto Vidigal. Recuperado em 30 de setembro de 2019, de https://www. fmcsv.org.br/pt-BR/biblioteca/dez-passos-para-implementar-um-programa-de-primeirissima-infancia-v/

Marino, Eduardo, \& Pluciennik, Gabriela Aratangy. (Orgs). (2015). Histórico e fundamentação teórica do Programa São Paulo pela Primeiríssima Infância (Programa São Paulo pela Primeiríssima Infância. Caderno A). São Paulo: Secretaria de Saúde. Recuperado em 20 de setembro de 2019, de http://portal. saude.sp.gov.br/resources/ses/perfil/gestor/primeirissima-infancia/a_primeirissima_infancia_compl.pdf

São Paulo. Governo do Estado. (2017a). Institui, junto à Secretaria de Desenvolvimento Social, o Comitê Gestor Estadual do Programa Criança Feliz e dá providências correlatas (Decreto Estadual № 62.492, de 23 de fevereiro de 2017). Diário Oficial do Estado de São Paulo, São Paulo. Recuperado em 30 de setembro de 2019, de http://www.desenvolvimentosocial.sp.gov.br/a2sitebox/arquivos/documentos/1451.pdf

São Paulo. Prefeitura Municipal. (2017b). Dispõe sobre princípios e diretrizes para a elaboração e implementação das políticas públicas pela primeira infância no Município de São Paulo e sobre o Plano Municipal pela Primeira Infância (Lei Municipal n 16.710 de 11 de outubro de 2017). Diário Oficial [da] República Federativa do Brasil, Brasília. Recuperado em 30 de setembro de 2019, de http://legislacao. prefeitura.sp.gov.br/leis/lei-16710-de-11-de-outubro-de-2017

São Paulo. Prefeitura Municipal. (2018). Regulamenta o artigo $8^{\circ}$ da Lei $n^{\circ} 16.710$, de 11 de outubro de 2017, que dispõe sobre a instituição de Comitê Gestor Intersetorial da Política Municipal Integrada pela Primeira Infância (Decreto Municipal n 58.294 de 28 de junho de 2018). Diário Oficial da Cidade de São Paulo, São Paulo. Recuperado em 30 de setembro de 2019, de http://legislacao.prefeitura.sp.gov.br/leis/ decreto-58294-de-28-de-junho-de-2018

São Paulo. Prefeitura Municipal. (2019a). Dispõe sobre a criação dos Comitês Gestores Regionais da Política Municipal Integrada pela Primeira Infância (Resolução SGM/CGIPMIPI n 1 de 21 de fevereiro de 2019). Diário Oficial do Estado de São Paulo, São Paulo. Recuperado em 30 de setembro de 2019, de http:// legislacao.prefeitura.sp.gov.br/leis/resolucao-1-de-21-de-fevereiro-de-2019

São Paulo. Prefeitura Municipal. (2019b). Dispõe sobre a criação da Comissão de Avaliação do Plano Municipal pela Primeira Infância e da Comissão Técnica da Primeira Infância (Resolução SGM/ CGIPMIPI $n^{\circ} 2$ de 29 de julho de 2019). Diário Oficial do Estado de São Paulo, São Paulo. Recuperado em 30 de setembro de 2019, de http://legislacao.prefeitura.sp.gov.br/leis/portaria-secretaria-do-governo-municipalsgm-cgipmipi-2-de-29-de-julho-de-2019 